First Peoples Child \& Family Review

An Interdisciplinary Journal Honouring the Voices, Perspectives, and Knowledges of First Peoples through Research, Critical Analyses, Stories, Standpoints and Media Reviews

\title{
Preventing Crime and Poor Health Among Aboriginal People: The Potential for Preventative Programming
}

\section{Lisa Monchalin and Olga Marques}

Volume 7, Number 2, 2013

URI: https://id.erudit.org/iderudit/1068845ar

DOI: https://doi.org/10.7202/1068845ar

See table of contents

Publisher(s)

First Nations Child and Family Caring Society of Canada

ISSN

1708-489X (print)

2293-6610 (digital)

Explore this journal

Cite this article

Monchalin, L. \& Marques, O. (2013). Preventing Crime and Poor Health Among Aboriginal People: The Potential for Preventative Programming. First Peoples Child \& Family Review, 7(2), 112-129. https://doi.org/10.7202/1068845ar

\section{Article abstract}

The purpose of this paper is to examine prevention programs, and discuss their potential for having an impact on reducing crime and poor health outcomes for Aboriginal people. A historical context is first outlined in order to provide a context for understanding the disproportionate amount of crime and related poor health outcomes affecting Aboriginal people. Risk factors for crime and health are identified, demonstrating their interrelatedness and overlapping nature, indicating that risk factors do not existing in isolation from each other. Existing crime prevention programs are subsequently discussed, paying particular attention to the intersection between evidence-based outcomes and programs offered at Aboriginal Friendship Centres. The use of prevention programs for preventing/reducing crime and related health costs (i.e. substance use/abuse, smoking, and/or addictions) has been positively established by existing research. Thus, it is suggested that these programs offered in Aboriginal centres, such as Aboriginal Friendship Centres, should be furtherexpanded and supported.
This document is protected by copyright law. Use of the services of Érudit (including reproduction) is subject to its terms and conditions, which can be viewed online.

https://apropos.erudit.org/en/users/policy-on-use/ 


\title{
First Peoples Child \& Family Review
}

An Interdisciplinary Journal Honoring the Voices, Perspectives and Knowledges of First Peoples through Research, Critical Analyses, Stories, Standpoints and Media Reviews

\section{Preventing Crime and Poor Health Among Aboriginal People: The Potential for Preventative Programming}

\author{
Lisa Monchalin ${ }^{a}$ and Olga Marques ${ }^{b}$ \\ a Faculty, Criminology Department, Kwantlen Polytechnic University, Surrey, British Columbia, Canada \\ b Teaching Faculty, Criminology and Justice, University of Ontario Institute of Technology, Oshawa, Ontario, Canada
}

\begin{abstract}
The purpose of this paper is to examine prevention programs, and discuss their potential for having an impact on reducing crime and poor health outcomes for Aboriginal people. A historical context is first outlined in order to provide a context for understanding the disproportionate amount of crime and related poor health outcomes affecting Aboriginal people. Risk factors for crime and health are identified, demonstrating their interrelatedness and overlapping nature, indicating that risk factors do not existing in isolation from each other. Existing crime prevention programs are subsequently discussed, paying particular attention to the intersection between evidence-based outcomes and programs offered at Aboriginal Friendship Centres. The use of prevention programs for preventing/reducing crime and related health costs (i.e. substance use/abuse, smoking, and/or addictions) has been positively established by existing research. Thus, it is suggested that these programs offered in Aboriginal centres, such as Aboriginal Friendship Centres, should be further expanded and supported.
\end{abstract}

Keywords: Crime prevention, Aboriginal peoples, risk factors, early intervention

\section{Introduction: Challenge and Overview}

The rates of crime ${ }^{1}$ affecting Aboriginal people ${ }^{2}$ as both victims and offenders are much higher as compared to non-Aboriginal people. It has been noted that Aboriginal people are three times more likely to experience violent victimization as compared to non-Aboriginal people (Brzozowski,

Corresponding author:

Lisa Monchalin, Criminology Department, Kwantlen Polytechnic University, Surrey Main 3881-14, 12666-72 Avenue, Surrey, BC, V3W 2M8, lisa.monchalin@kwantlen.ca
Taylor-Butts, \& Johnson, 2006). Furthermore, the proportion of Aboriginal peoples incarcerated is $12 \%$ higher for Aboriginal peoples (72.2\%) than for non-Aboriginal peoples $(59.9 \%)^{3}$ (Public Safety Canada, 2011).

The overrepresentation of Aboriginal people in terms of rates of risky health behaviours across Canada is also significant. According to the

1 Crime is defined as an act committed or omitted, such as negligence, in violation of the Criminal Code of Canada.

2 When discussing "Aboriginal people" this is in reference to the original inhabitants of Turtle Island (referred to as North America). This includes First Nations, Inuit and Métis peoples. It is recognized that this term is an institutional construct of the state, and it incorrectly lumps people of many diverse backgrounds and cultures into one grouping.

3 As of April 10, 2011. 
First Peoples Child \& Family Review, Volume 7, Number 2, 2013

2000/01 Canadian Community Health Survey 51.4\% of the off-reserve Aboriginal population were smokers, 1.9 times higher as compared to the non-Aboriginal population (Tjepkema, 2002, p. 7). Off-reserve Aboriginal people do comprise a smaller proportion of weekly drinkers as compared to non-Aboriginal people; however, they do report higher levels of heavy drinking as compared to non-Aboriginal peoples (Tjepkema, 2002, p. 8).

These poor health and risk behaviours are frequently associated with crime. In fact, many risk factors for poor health and crime are interrelated (for examples of risk factors see, Lambertus, 2007; Loppie Reading \& Wein, 2009; Sanders, Markie-Dadds \& Turner, 2003; Totten, 2009; World Health Organization [WHO], 2002, 2004; Zahradnik, Stewart, O'Connor, Stevens, Ungar, \& Wekerle, 2010). There is a significant body of evidence demonstrating that that preventative early intervention programming can have a major impact on the reduction of risk factors associated with poor health and crime (Farrington \& Welsh, 2007, p. 61-65; Mushquash, Comeau \& Stewart, 2007; Sanders, et al, 2003). Thus, the main goal of the paper is to explore the potential for preventative programming to reduce crime and poor health for Aboriginal people.

\section{Colonialism, Policies of Assimilation and Residential Schools}

In part, many of these interrelated crime and health-related risk factors have been said to stem from residential school experiences and other policies of assimilation, and colonialism (Corrado \& Cohen, 2003; Cote \& Schissel, 2008; Monchalin, 2010, 2012). Throughout history many policies were enacted with the goals of assimilation and integration. In 1869 there was the Act for the Gradual Enfranchisement of Indians. This Act marked the creation of invasive legislative policies which would initiate interference in the internal affairs of Aboriginal peoples. In 1876, the Indian Act was borne which consolidated various "Indian" policies into one place.

In 1879, Prime Minister Sir John A. Macdonald followed a recommendation based on a report written by Nicholas Flood Davin, and commonly referred to as the Davin Report, a report he commissioned. The Davin Report looked to the American model of Indian Industrial Schools, and recommended that Canada follow the U.S. model of "aggressive assimilation." As a result, in 1831 the first Indian residential schools opened in Canada, with the last one closing in 1998 (Chansonneuve, 2007, p. 10). The aim of residential schools was to erase all traces of Aboriginal cultures including languages, beliefs, customs and spiritual traditions (Chansonneuve, 2007, p. 7).

Many Aboriginal peoples initially supported the formation of church-run residential schools, believing that a knowledge of the English language and agricultural and trade skills would increase their opportunities (Furniss, 1995, p. 21). This was the hope for many Aboriginal nations of Upper Canada at the time when the first schools were established (Furniss, 1995, p. 21). However, by the 1860s support for Christianity and mission education in Upper Canada started to diminish (Furniss, 1995, p. 21). Tribal Councils started to reject the mission program because they disagreed with the dividing of their communities as well as the dismantling of their cultures (Furniss, 1995, p. 21). As the true purpose of the residential schools was to create Christianized, and "civilized" Aboriginal communities (Furniss, 1995, p. 20; Haig-Brown, 1991, p. 69).

Throughout students' tenure at residential schools, many were sexually, physically, and psychologically abused (Chansonneuve, 2007, p. 11; Chrisjohn, Young \& Maraun, 2006, p. 49-50; Corrado \& Cohen, 2003, p. 41; Cote \& Schissel, 2008, p. 224; Fournier \& Crey, 2006, p. 141-142, Grant, 1996, p. 225-231; Kelly, 2008, p. 24; Milloy, 1999, p. 298; Shawanda, 2010, p. 29). Sexual abuse took many forms, including forced sexual fondling or touching, oral-genital sex, and sexual 


\section{Preventing Crime and Poort Health Among Aboriginal People}

intercourse by those in authority over the children (Chansonneuve, 2007, p. 11). Founier and Crey (2006), describe an experience by Emily Rice, who had left Kuper Island residential school at the age of 11 in 1959, explaining that:

She had been repeatedly assaulted and sexually abused by Father Jackson and three other priests, one of whom plied her with alcohol before raping her. A nun Sister Mary Margaret, known for peeping at girls in the shower and grabbing their breasts, was infuriated when Emily resisted her advances. "She took a big stick with bark on it, and rammed it right inside my vagina," recalls Rice...in the years that followed, Emily would have to twice undergo reconstructive vaginal surgery, and she suffered permanent hearing loss. (p. 141-142)

Children would be physically punished for speaking their language, which would include various forms of public humiliation, putting them on a bread and water diet, or pushing needles through their tongues (Chansonneuve, 2007, p. 11; Haig-Brown, 1991, p. 82). Children were also harshly punished for a variety of things, ranging from chewing gum to wetting the bed (HaigBrown, 1991, p. 83), where the punishment for wetting the bed would be for the child to take their pants down in front of all of their peers and then be brutally whipped (Haig-Brown, 1991, p. 83). Punishment for bed wetting also included the forcing of children to wear diapers, or to wear soiled clothing (Chansonneuve, 2007, p. 11). Psychological abuse also included children being continually shamed and called names such as "savage" and/or "heathen" (Chansonneuve, 2007, p. 11).

Evidence of the effects of residential schools have been well documented in residential school survivors' stories (see Cote \& Schissel, 2008; Shawanda, 2010), as well as through research studies, such as examinations of residential school survivors' clinical case study files (see Corrado \& Cohen, 2003). There has been a legacy of negative impacts of the residential school system and the Government of Canada's policy of assimilation identified (Corrado \& Cohen, 2003; Gagné, 1998; Jacobs \& Williams, 2008, p. 126; Kirmayer, Brass, Holton, Paul, Simpson, \& Tait, 2007, p. 69; Monture-Angus, 1998, p. 363; Rice \& Snyder 2008, p. 49). These include: loss of culture, language, traditional values and family bonding, as well as a decrease in life skills and parenting skills, dependency on others, among others (Furniss, 1995, p. 31; Jacobs \& Williams, 2008, p. 126; Loppie Reading \& Wein, 2009, p. 22).

Although the residential school system was ultimately disbanded, legacies of negative impacts remain. Seven generations of Aboriginal children went through residential schools. Clergy, priests and nuns became children's primary caregivers. These primary caregivers were the people who ended up committing horrible acts against these children (Rand, 2011, p. 58). Having families ${ }^{4}$ broken apart and children being raised by abusing strangers has left many devastating impacts on the future generations of those families who were forced into these horrific circumstances. According to Fournier and Crey (1997) by the late 1940's, four or five generations of Aboriginal people had come out of residential schools as angry, poorly educated abused strangers "who had no experience in parenting" (p. 82). Some residential school survivors and their descendants now have a very hard time establishing trusting or supportive attachments with family members, including their spouses, children and grandchildren (Chansonneuve, 2007, p. 20).

Literature has also shown that many residential school survivors suffer from stressful experiences, which include many crime related risk factors such as disconnected families, single parent families, to poor child rearing and supervision, and family violence. These risk factors have

4 "Families" is in reference to a group living together, typically encompassing parent(s), and children. This can also include extended family members such as grandparents, cousins, aunts and uncles. It may also include those adopted into the family. 
First Peoples Child \& Family Review, Volume 7, Number 2, 2013

also contributed to further interrelated risk factors such as low educational attainment, substance abuse and addictions, unemployment, substandard living conditions, and high residential mobility, which subsequently have led many survivors and their family members down similar roads (Chansonneuve, 2007; Corrado \& Cohen, 2003; Cote \& Schissel, 2008; Gagné, 1998; Jacobs \& Williams, 2008; Rice \& Snyder, 2008; Totten, 2009, p. 137-138).

Colonialism has had drastic implications on Aboriginal peoples. In the context of the Canadian Aboriginal experience, colonialism specifically involves the dislocation and disconnection of Aboriginal peoples from their traditional lands. This involved the stripping away of peoples identity, rights, and forcing peoples under the control and governing influence of-in this casethe European settlers. Furthermore, although colonialism might have been more "visible" when reflecting on the past, it still remains, and is ongoing. Today, we are in an era of contemporary colonialism, where the dominate voice is still rooted and based on the settler imperative (Alfred \& Corntassel, 2005, p. 597). These new generations of contemporary settlers have shadowed the order bestowed to them by their imperial forefathers' colonial legacy (Alfred \& Corntassel, 2005, p. 598). Colonizers of today instead follow covert practices to reach goals. They have internalized myths about Aboriginal peoples which have now permeated social institutions and current value systems.

Causal factors related to ongoing colonialism and affecting Aboriginal people, includes structural violence, including racism, marginalization, and exclusion from social and economic participation. Exclusion and marginalization is the notion used to describe obstacles faced by certain social groups (in this case, Aboriginal people), obstructing them from the labour market and involvement in society's core institutions (Jaccoud \& Brassard, 2003, p. 132). Exclusion and marginalization are an aspect of poverty, economic insecurity, and social isolation (Jaccoud \& Brassard, 2003, p. 132).

Given the history of racist policies and agenda's which sought to eradicate Aboriginal peoples, the focal tenants of these polices and agendas have essentially permeated political structures and have infused social institutions of today. Racism has become institutionalized. Therefore, it may have become more subtle, yet, no less damaging. Barriers of institutionalized racism are what contribute to the lack of access to society's core institutions and play a large part in creating a major hurdle to full participation in the labour market.

\section{Interrelated Health and Criminogenic Risk Factors}

Recognizing the accumulated negative outcomes of colonialism and residential schools offers a context for understanding why many Aboriginal people suffer from multiple risk factors related to crime and poor health today (Monchalin, 2012). This is not to say that risk factors for crime and poor health are specific to Aboriginal people, or that there is a biological difference that predisposes Aboriginal people to such factors. To say this would be an incorrect colonial and outright racist assumption, and one that does not take into account the current, and historical, positioning of Aboriginal people in Canadian society. However, it has been shown that individuals, particularly children and youth, of different racial or ethnic backgrounds living in Canada are often faced with different set of extraneous predisposing factors, and often culturally-appropriate coping strategies are not readily accessible (Marques 2010).

All people, regardless of race or ethnic background, are subject to several risk determinants related to crime and poor health. Research shows that any person who experiences risk factors 


\section{Preventing Crime and Poort Health Among Aboriginal People}

related to crime puts them at a higher chance to be a victim or offender of crime. The more risk factors one faces, the higher the chances go up. The presence of one risk factor increases the risk of crime and multiple risk factors cause greater increases (Monchalin, 2012, p. 27). This is not to say that this is an absolute, as an individual may experience several crime related risk factors and not be involved in crime, however, it would be more likely that they might be given that they experience such factors (Monchalin, 2012, p. 27). The same reasoning can be applied with health related risk factors. For example, noted risk factors for heart disease include smoking and a high fat diet. Therefore, a person who exhibits these behaviours, compared to someone who does not, would be more likely to have the adverse outcome. However, it is not an absolute.

Given that many Aboriginal people have faced demonstrated atrocities, and continue to face the consequences of on-going colonialism, they are more likely to be confronted with more risk factors for crime and poor health, as well as with less access to resources to mitigate their effects. It cannot be discounted that non-Aboriginal people do not have histories nor do not confront similar realities of colonialism and institutionalized racism.

Risk factors found to be highly associated with poor health outcomes also include many crime related risk factors (Loppie Reading \& Wein, 2009; Sampson \& Laub, 1993; Sanders et al., 2003). These include: living in poverty and poor housing, lack of access to education, addictions, poor parenting skills, poor supervision and monitoring of children, lack of discipline or parental reinforcement, family violence and crime, and marriage and family breakdown, which have all been found to strongly influence children's development (Farrington \& Welsh, 2007, p. 61-62; La Prairie, 1994; Sampson \& Laub, 1993; Sanders et al., 2003; Waller, 2006).

In particular, research shows that a lack of a positive relationship with parents; insecure attachment; harsh, inflexible or inconsistent discipline practices; marital inconsistency and breakdown; scarce supervision of and a lack of a strong relationship with children, increases the risk that children will develop increased health problems (Coie, 1996; Farrington \& Welsh, 2007, p. 61-62; Loeber \& Farrington, 1998; Sanders et al., 2003, p. 1). These include major behavioural and emotional problems, depression, substance abuse, antisocial behaviour, as well as having more experiences with crime (Coie, 1996; Farrington \& Welsh, 2007, p. 61-62; Loeber \& Farrington, 1998; Sanders et al., 2003, p. 1).

There are many studies and reports which have confirmed the correlation between risk factors such as lack of parental supports, and higher rates of crime (Farrington \& Welsh, 2007). Research has shown that family conflict and poor parenting skills are risk factors commonly associated with adverse developmental outcomes in children including drug abuse, delinquency, ${ }^{5}$ increased conduct problems, and academic underachievement, as well as intra-familial child abuse (Olds et al., 1999; Sanders, et al., 2003; Schweinhart 2005). Furthermore, many researchers have pointed out the importance of early childhood experiences as an important factor in behaviour in later life (Linden, 2001, p. 7).

5 "Delinquency" includes actions which break rules, obligations or duties as set out by parents, guardians, and/or the law. 
First Peoples Child \& Family Review, Volume 7, Number 2, 2013

Many Aboriginal youth ${ }^{6}$ suffer from risk factors for poor health outcomes and criminal behaviour (Totten, 2009, p. 137-138; Zahradnik et al., 2010, p. 209). Research has demonstrated many poor health outcomes that are associated with crime. Some commonly cited health factors include depression, anxiety, emotional distress, and having physical, mental or cognitive disabilities (Lambertus, 2007, p. 46; Sanders et al., 2003). Research has also demonstrated many risky health behaviours associated with crime. Some commonly cited factors include poor prenatal care as well as drinking and smoking during pregnancy, substance abuse/misuse, addictions, family violence and disintegration, neglect, and abuse (Comack et al., 2009, p. 1-5; Loppie Reading \& Wein, 2009).

Poor health outcomes and risky health behaviours not only have differential impacts on health throughout one's lifespan, but the resulting health issues may themselves create conditions (i.e., additional risk factors) that subsequently influence health (Reading, 2009). For example, poverty is linked with increased alcohol abuse (Cerdá et al., 2010) and other substance abuse, which can lead to stressed family environments and reduced social support, which are correlated to depression (Loppie Reading, \& Wein, 2009, p. 3).

Health inequalities can be explained, in part, by the fact that many Aboriginal peoples have lower socio-economic status; a factor widely known to be associated with poor health (Tjepkema, 2002). Additionally, lower socio-economic status among Aboriginal people is also a factor widely known to be associated with crime (La Prairie \& Stenning, 2003). Many risk factors for crime and health are interrelated and overlapping, and many do not exist in isolation from other factors (Mikkonen \& Raphel, 2010; WHO, 2002, p. 33).

Another related risk factor related to both poor health and crime is unemployment and lack of job security. Unemployment is also associated with physical and mental health problems such as stress, anxiety, depression, and increased suicide rates (Mikkonen \& Raphel, 2010).

Physical environments, such as poor living conditions including crowded housing conditions have been found to be been associated with both crime and stress (Fitzgerald \& Carrington, 2008; Knotsch \& Kinnon, 2011, p. 28; La Prairie, 1992: 2002; Loppie Reading \& Wein, 2009, p. 3; Reading, 2009, p. 13). Poor and crowed housing conditions can also indirectly be a factor in substance abuse and parenting difficulties, which may in turn negatively affect children's functioning in school (Knotsch \& Kinnon, 2011, p. 27; Loppie Reading \& Wein, 2009, p. 3). Over-crowded living conditions have also been found to be correlated to youth substance abuse and violence as well as increased aggression in children (Knotsch \& Kinnon, 2011, p. 27; Loppie Reading \& Wein, 2009, p. 4). As explained by Loppie Reading and Wein (2009) if a suboptimal environment is present, children and youth may not only be challenged with obstacles to ideal "physical, emotional, intellectual, and spiritual development," but the problems they may face will most likely generate added stressors for their families and/or communities (p. 3-4). Although the numbers are declining, ${ }^{7}$ Aboriginal people are still more likely than non-Aboriginal people to live in crowded conditions (Statistics Canada, 2006).

6 When discussing "Aboriginal youth, "this includes First Nations, Inuit and Métis youth. Age ranges can vary however typically encompass youth aged 15 to 24 . More recently however, this has increased to include those up to 35, or sometimes beginning at 13. Statistics Canada defines youth as those between the ages of 15 to 24 . Various Aboriginal organizations also have their own definitions. For example the Congress of Aboriginal Peoples, The Métis National Council and the National Association of Friendship Centre use the 15 to 24 definition. The Aboriginal Healing Foundation, the Native Women's Association of Canada and the Assembly of First Nations define youth as those between the ages of 18 to 24. The Inuit Tapiriit Kanatami defines youth with a broader range inclusive of those 13 to 29. The Empowering Indigenous Youth in Governance and Leadership (EIYGL) youth led Aboriginal initiative, encompasses those aged 15 to 35. The National Aboriginal Role Model Program encompasses youth aged 13 to 30.

7 In 2006, $11 \%$ of Aboriginal people were living in homes with more than one person per room, which is down from $17 \%$ in 1996 . 


\section{Preventing Crime and Poort Health Among Aboriginal People}

Similarly, family violence, which is experienced by Aboriginal people at a rate twice as high as compared to non-Aboriginal people (Perreault, 2011, p. 10), directly impacts all aspects of family health, particularly women's health, with a resulting negative impact on the physical and emotional health of children (Loppie Reading \& Wein, 2009, p. 6; WHO, 2004, p. 33). Physical health impacts on children might include broken bones, fractures, and burns, among others (National Collaborating Centre for Aboriginal Health [NCCAH], 2009. Emotional health impacts might include depression, low self-worth, or anxiety, among others (NCCAH, 2009). Furthermore, according to the NCCAH (2009) family violence is also correlated with poor socioeconomic circumstances, which in turn can also lead to stress, as well as incapacity to cope, thus, leading to occurrences of violence (p. 1).

A widely discussed risk factor related to both poor health and crime is also the abuse and/ or misuse of alcohol (Brems, 1996; Segal, 1999; Brzozowski et al., 2006, p. 138; Yuan, Koss, Polacca, \& Goldman, 2006). According to the 2000/01 Canadian Community Health Survey, $22.6 \%$ of Aboriginal people living off-reserve reported being heavy drinkers compared to $16.1 \%$ of non-Aboriginal people (Tjepkema, 2002). Heavy drinking is linked with suicidal behaviour, and suicide and deaths from unintentional injury (Borowsky, Resnick, Ireland, \& Blum, 1999; Kettl \& Bixler, 1993; Seale, Shellenberger, \& Spence, 2006, p. 2). This risk factor, abuse and/or misuse of alcohol, has also been identified as being related to increases in excessive smoking, the health effects of which are clearly expressed in the high prevalence of cardiovascular disease in Aboriginal populations (Loppie Reading \& Wein, 2009, p. 6; Retnakaran, Hanley, Connelly, Harris, \& Zinman, 2005; Tjepkema, 2002, p. 7). The abuse of drugs and alcohol also increases risk for accidents, illness, disease and violence (Chansonneuve, 2007) and is often a factor in spousal homicide (Statistics Canada 2005).

Suicide rates among First Nations communities are about twice that of the total Canadian population (Kirmayer et al., 2007; Kirmayer, Simpson, \& Cargo, 2003). The rate among Inuit people is even higher, with rates 6 to 11 times higher than the general population (Kirmayer et al., 2007, p. 1). However, there is ample variation in suicide rates when comparing different Aboriginal communities in Canada (Hallett et al., 2007; Kirmayer, Fraser, Fauras, \& Whitely, 2009 , p. 13). Chandler and Lalonde (1998) suggest that Aboriginal youth and young adults whose identity is weakened or challenged by essential or drastic individual or cultural change are put at exceptional risk of suicide because they lose vital guarantees that are essential to their security and welfare. They explain this as being a lapse in what they refer to as "cultural continuity." Any threat to personal or cultural identity poses a threat to community security and welfare, for example, limited access to traditional lands, and the lack of preservation of Aboriginal language would be an upset to cultural continuity (Hallett et al., 2007, p. 393). It is for reasons such as these that youth and young adults who are living through instants of this particularly dramatic change (thus interrupting their cultural continuity) experience high rates of suicide. More recently, Kral (2011) argued that suicide is a learned behaviour. Kral conducted research with Inuit for 17 years on suicide and cultural change, finding that it was common for Inuit youth to talk about and copy other suicides. Looking to patterns of suicide among Indigenous people outside of Canada, high rates of suicide are found among numerous Indigenous peoples who have encountered colonization or other forms of marginalization or cultural oppression (Kirmayer et al., 2009, p. 13). A similar notion is also discussed by Kral (2011), who found that colonialism dramatically disrupted family and romantic relations, also impacting high rates of suicide (p. 8).

Risk factors related to Aboriginal youth suicide have been summarized in a report by Kirmayer et al., (2009), and have included the following: male gender, victim of violence or physical abuse, 
victim of bullying (for girls), perpetrator of violence or physical abuse, perpetrator of bullying (for boys), physical fighting, alcohol use, inhalant or solvent use, school problems, poor family environment, relative poverty, among others (p. 19).

Alcohol use has also been found to be correlated to homicide, family violence, and foetal alcohol syndrome (Seale et al., 2006, p. 2). Poor prenatal care as well as alcohol and tobacco use during pregnancy has also been found to be correlated to poor physical, emotional, and intellectual growth among Aboriginal children (Loppie Reading \& Wein, 2009, p. 6). Furthermore, tobacco use during pregnancy has also been correlated to the mothers' illicit drug use, and non-completion of high school, among other factors (see Heaman \& Chalmers, 2005).

Another widely discussed risk factor related to both poor health and crime affecting Aboriginal people is poverty (La Prairie, 1994, 2002; Lambertus, 2007; Latimer \& Foss, 2004; Loppie Reading \& Wein, 2009; Tjepkema, 2002). This includes lack of access to material resources, such as nutrient rich food, which leads to high rates of obesity and diabetes, resulting in poor cardiovascular health as well as poor kidney health (Loppie Reading \& Wein, 2009, p. 9; Tjepkema, 2002). Lack of exercise and poor diet has been associated with the epidemic of Type II Diabetes among Aboriginal adults and increasing rates among Aboriginal youth (Tjepkema, 2002, p. 7; Loppie Reading \& Wein, 2009, p. 6-7). The prevalence of diabetes among the off-reserve population is double that of the non-Aboriginal population (Tjepkema, 2002: 3).

There are also many health related consequences resulting from living in poverty while one is pregnant (Larson, 2007). This includes greater increased risks, preterm births, growth restrictions and possible infant death (Larson, 2007). In turn, children born to impoverished parents are at increased risk for delayed cognitive development and poor school performance, as well as behaviour problems throughout their youth and adolescence (Larson, 2007).

Poverty is also linked to social exclusion/marginalization, low social cohesion and increased crime (Jaccoud \& Brassard, 2003; Loppie Reading \& Wein, 2009, p. 9). In turn, social exclusion/ marginalization impedes some from pursing education and/or training (Loppie Reading \& Wein, 2009 , p. 9). Most significantly is the lack of control poverty creates, with resulting anxiety, feelings of hopelessness, and low self-esteem (Loppie Reading \& Wein, 2009, p. 9). This, and other types of psychosocial stress, has been correlated to crime and violence, addictions, poor parenting, and lack of social support (La Prairie, 1994; Lambertus, 2007; Loppie Reading \& Wein, 2009, p. 9). A recent study has also linked parental psychosocial stress to increases in asthma in their children (see Lange et al., 2011).

Furthermore, suicide has also been identified as being correlated to poor mental health and substance abuse (Brems, 1996: Kirmayer et al., 2009), which is in turn, also linked to social exclusion/marginalization and poverty (Loppie Reading \& Wein, 2009, p. 10). Mcleod and Shanahan (1996) have established that children's mental health is directly related to their family's history of living in poverty, and that children who grow up in poverty are more likely to have higher levels of depression and anti-social behaviour.

\section{Evidence for Prevention Programs}

Research has also overwhelmingly shown that young people may be the most amenable to intervention (Linden, 2001). There are many reviews of research confirming the importance of 


\section{Preventing Crime and Poort Health Among Aboriginal People}

early intervention for children and youth, which include the tackling of risk factors related to crime (Farrington \& Welsh, 2007; Sherman et al., 1997; Waller, 2006; Welsh \& Farrington, 2006). Research shows also that prevention programming can achieve reduced health costs (Dishion \& Andrews, 1995; Sandler, Schoenfelder, Wolchik \& MacKinnon, 2011; Smith et al., 2006). These reduced health costs include reductions in substance use/misuse, smoking, and addictions (Dishion \& Andrews, 1995; Sandler et al., 2011), as well as foetal alcohol spectrum disorder (FASD) (Astley, 2004; Streissguth, et al., 2004).

Given Aboriginal peoples history of being dislocated from families, losing familial bonds, and undergoing obstructed parenting resulting from residential schools, family-focused parenting programs and other early intervention type programs, we argue, might have the potential for having an impact on healing, repairing or preventing some of these resulting intergenerational impacts.

There is a large body of evidence conducted on non-Aboriginal people that shows that prevention which seeks to tackle risk factors, can dramatically reduce such factors (for example see, Carr, 2006; Dishion \& Andrews, 1995; Flicker, Turner, Waldron, Brody, \& Ozechowski, 2008; Hahn, Leavitt \& Aaron, 1994; Schweinhart, 2005; Sexton \& Turner, 2010; Smith, Sells, Rodman $\&$ Reynolds, 2006). However, compared to general evidence-based research, that which is specific to Aboriginal people is much less (Monchalin, 2012). This means that many of the projects which show evidence for risk factors were not conducted on Aboriginal specific programs, or on programs that had a high degree of Aboriginal participation (Monchalin, 2012). However, more recently what might be termed as "promising" prevention evidence focused on Aboriginal people has been growing (for example see Carter, Straits \& Hall, 2007; Gilchrist, Schinke, Trimble \& Cvetkovich, 1987; Mushquash et al., 2007; Turner, Richards \& Sanders, 2007). This type of evidence is beginning to be amassed in reviews of such research (for example see Bodson et al., 2008: 141-174; Capobianco, Shaw \& Dubuc, 2003; Totten 2009; Monchalin 2012).

Canada’s National Crime Prevention Centre is also building up an evidence library containing "promising" evidence-based Aboriginal programs. For example, The Kwanlin Dun First Nation's Project was a family-focused prevention program. It incorporated culturally specific components such as recognition of the extended family, and various cultural preferences (Public Safety Canada, 2007). The program was tested in 5 different sites across Canada including three sites in Edmonton (Norwood Child and Family Resource Centre, Bent Arrow Traditional Healing Society, and Terra Association), in Charlottetown, Prince Edward Island, and the Kwanlin Dun First Nation Healthy Families Program in Whitehorse, Yukon (which was the Aboriginal specific site). The aim of the program was to reduce the risk factors associated with crime, including child abuse and neglect and exposure to domestic violence (Public Safety Canada, 2007). This program targeted parents with children between the ages of 0-6 who were considered at high risk of crime and victimization. It employed family home visitations by family support workers. The visitations incorporated three main components including, parenting, child development and parent-child interaction.

Both process and outcome evaluations were conducted on the program which were administered over a 32-month period, between July 1999 and December 2001 (Public Safety Canada, 2007). Pre- and post-test data was collected across the five different sites, with 370 clients (Public Safety Canada, 2007). The families in Prince Edward Island were used as the comparison group. Some of the key evaluation findings showed that, out of the five sites studied, four demonstrated 
improvements in family functioning. All programs experienced improvements in parents' expectations of their children, and their levels of empathy and beliefs about punishment.

Parents felts that the best aspects of the program included: learning about child development and parenting, as well as gaining access to (and also learning about) local community services. They also noted their positive relationship with their family support worker. Parents also felt that the social support they received assisted them in becoming more child-focused, and they thought it enhanced their coping skills and assisted them in relationship building with others. In addition, only $5 \%$ of the program group had involvement with child welfare authorities, compared to $35 \%$ of the comparison group (Public Safety Canada, 2007).

\section{Aboriginal Friendship Centres: Offering Preventative Programming}

Many preventative programs are being delivered in Aboriginal centres and other nongovernment organizations in Canada (Monchalin, 2012). For example, Friendship Centres offer many essential programs for Canada's urban Aboriginal population. They are centres which were not only created by Aboriginal peoples, but are also run by and for Aboriginal people. Across Canada there are currently 119 Friendship Centres that are members of the National Association of Friendship Centres. These Friendship Centres offer a variety of social programming initiatives for children, youth and families; these have included sports, recreation, cultural education, teen parenting skills, family violence intervention, family support programs, substance abuse intervention, job skills training, and others.

Programming such as this may prove effective in reducing risk factors experienced by many Aboriginal peoples, and thus has potential to reduce the large degree of victimization, crime and poor health affecting some Aboriginal peoples. Even though the many programs offered through the Friendship Centres may not be labelled as "prevention," they are similar to what "effective prevention" is considered to be by researchers in the field (for example see Waller, 2006). These types of programming are sometimes referred to as "Crime Prevention through Social Development" and/or "Secondary Prevention" (see Hastings \& Jamieson, 2002; Waller, Sansfaçon \& Welsh, 1999; Waller \& Weiler 1984). These are programs that focus on early identification and intervention in the lives of individuals or groups who are considered at-risk; and once these at-risk individuals, situations, places, or opportunities are identified, interventions designed to modify those risk factors are implemented with the hope that they might prevent undesired outcomes while increasing positive outcomes.

There is much research revealing the effectiveness of providing early intervention programming for young mothers, children and youth (see Crooks, Wolfe, Hughes, Jaffe \& Chiodo, 2008; Mushquash et al., 2007; Olds et al., 1999; Sanders et al., 2003; Schweinhart, 2005; Turner et al., 2007). Friendship Centres across Canada deliver many similar programs as those described in much of the prevention programming literature (see Farrington \& Welsh, 2007; Greenwood et al., 2001; Sherman, Farrington, Welsh, \& Mackenzie \& 2002; Sherman et al., 1997; Waller, 2006).

For example, many Friendship Centres, such as the Odawa Native Friendship Centre in Ottawa, the United Native Friendship Centre in Fort Frances, The Indian Friendship Centre in Sault Ste. Marie, and the Fort Erie Native Friendship Centre (among others), offers an Aboriginal Healthy Babies Program that aids mothers with young infants. It provides information on taking care of their babies in a culturally relevant way. The program maintains a network of health and 


\section{Preventing Crime and Poort Health Among Aboriginal People}

social service providers to ensure that Aboriginal mothers with young children (prenatal to age six), have access to a range of social development, prevention and early intervention activities and initiatives. For example, the main tenet of the program is to provide home visiting services to urban Aboriginal families. Such services include parenting education and support, child development resources, meal planning and preparation, and traditional teaching in child rearing.

There is a large body of research evidence revealing that programs targeting young at-risk mothers can be effective in reducing child abuse. For example, one evidence-based project which is continually cited for its effectiveness is the Elmira (New York) Prenatal/Early Infancy Project (see Sherman et al., 2002; Sherman et al., 1997; Waller, 2006; Greenwood et al., 2001). This project was a randomized controlled trial which took a sample of $400^{8}$ women in the Elmira, New York area who were low income (85\%), unmarried, or younger than 19 years of age. The 400 participants were divided into two groups, with 200 receiving the home visits and the other 200 relying on the standard services being offered in the area at the time (Olds et al., p. 53). The home visits program consisted of public health nurses visiting these mothers. Similar to the Aboriginal Healthy Babies Program the nurses provided mothers with information on the health and development of their children while assisting them in developing supportive relationships with friends and family and other essential health and human services (Olds et al., p. 49).

An evaluation of the Elmira Program revealed that the mothers who took part in the program were less likely to abuse and neglect their children. There was an $80 \%$ reduction in verified cases of child abuse and neglect (through to age 15) as compared to a control group (Karoly et al., p. 32; Olds et al., p. 44,). Mothers in the program were also found to avoid substance abuse and other criminal behaviours more effectively when compared to a control group (Olds et al., p. 44). In addition, the children of the mothers who received the programming had $56 \%$ fewer arrests by age 15 as compared to a control group (Olds et al., p. 44, Waller, 2006, p. 26).

Furthermore, almost all Friendship Centres offer social development programming for children, teens and youth. A popular program offered by many of the Friendship Centres is the Akwe:go Program. This program provides a variety of social development activities to youth ages 7 to 12 . For example, it offers life skills training, anger management training, and provides many different social supports that address poverty-related self-esteem issues. It also provides guidance on reducing victimization, on how to avoid peer pressure, and out-reach support to children in care. It promotes health and physical education and also supports children with Fetal Alcohol Spectrum Disorder.

Programs offering early intervention assistance for children, teens and youth have been cited as effective by many crime prevention researchers (see Farrington \& Welsh, 2007; Sherman et al., 2002; Sherman et al., 1997; Waller, 2006; Welsh \& Farrington, 2002). One commonly cited program is the Quantum Opportunities Project. This was a demonstration project which was carried out in five different U.S cities-San Antonio (TX), Philadelphia (PA), Milwaukee (WI), Saginaw (MI), and Oklahoma City (OK) - beginning in September 1989 (Hahn et al., 1994, p. 6). The program focused its prevention efforts on disadvantaged teens ${ }^{9}$ and provided them with after-school developmental programming.

Similar to many programs offered through the Friendship Centres for teens and youth, the Quantum Opportunities program provided educational activities including tutoring, computer skills training,

8 Five hundred women were invited to participate; four hundred women actually enrolled (Olds et al., p. 53).

9 According to Hahn et al., (1994) this included high school aged youth who were from families receiving public assistance (p. 6). 
life and family skills training, and guidance activities such as planning for post-secondary education or employment following graduation (Hahn et al, 1994; Greenwood et al., 2001).

An evaluation comparing the program and control groups was conducted throughout the duration of the program. This started in September 1989 (before the programming was delivered); questionnaires were given to all participants in both groups. The questionnaires were given to both groups again once the program started, first in the fall of 1990, then in 1991, and again in 1992 (Hahn et al., 1994: 7). Those who received the programming were more likely to graduate from high school and to enrol in post-secondary educational institutions. Moreover, they were more likely to receive an honour or award, were less likely to become pregnant, were less likely to be high school dropouts, and were therefore less likely to lead a life of crime as compared to the non-programming groups (Hahn et al., 1994; p. 15).

Furthermore, there is also research emphasizing the importance of providing programing in a culturally appropriate manner (see Monchalin, 2012). All programs provided at the Friendship Centres have an Aboriginal cultural component to them, or are delivered using Aboriginal traditional teachings and/or knowledge.

Programs, such as those identified above, as well as those provided by various Aboriginal Centres (both on and off reserve) may have the opportunity to make differences in the lives of Aboriginal peoples. Thus, offering a more viable strategy to reduce risk factors found to result in high rates of victimization, crime and poor health related outcomes among Aboriginal peoples.

\section{Discussion and Next Steps}

If reductions in crime and poor health affecting Aboriginal peoples are to be reduced, prevention programs tackling interrelated criminogenic and health risk factors could play a large role in achieving reductions. Utting (2003) suggests parenting education and family support as among the more promising potential contributors to a solution (p. 243).

A child or youth's socio-cultural context, including the family, influences learned healthy behaviours (Crossman, Sullivan \& Benin, 2006). Early socialization and child development within the family and community contexts can contribute significantly to the development and maintenance of positive health indicators into adulthood (Kendall \& Li, 2005). Consistent with an ecological perspective that considers the interpersonal environment an important influence on the behaviour of a given population, the family is also seen as a significant source of behavioural influence (Chea \& Nelson, 2004). Children are also held in high regard in many traditional Aboriginal cultures. The family unit itself is often large and includes members of the extended family who assist in helping to raise the children (Dilworth-Anderson \& Marshall, 1996). Therefore, programs focusing on children may also be favourable to those whose culture places importance on children and family.

However, before implementing a new prevention program based on similar models described in this paper, a thorough understanding of the population the program is seeking to serve is essential, in terms of needs, culture and any other specifics. Program models which take into consideration specific cultures, traditions and experiences of the people it is seeking to serve is important. Given Aboriginal peoples history of residential schools, and the resulting legacy from many of these experiences, programs which acknowledge this history, as well as acknowledge ongoing colonialism and current experiences, could pose as very beneficial. Programs that take into consideration the specific realities faced by Aboriginal youth such as child welfare 


\section{Preventing Crime and Poort Health Among Aboriginal People}

overrepresentation and forced off-reserve relocation for high-school education are also vital. This is also why Aboriginal centres, which provide programs by and for Aboriginal people, are essential, given they will have a better understanding and awareness of Aboriginal specific realities. Utilizing the already existing Friendship Centres and/or other Aboriginal organizations, and providing them with the proper resources, may play a role in breaking the multi-generational cycles of crime, disadvantage, and poor health that have plagued communities for far too long.

However, Aboriginal Friendship Centres have not received an increase in their core funding since 1988 (National Association of Friendship Centres, p. 8). Instead they are left to compete for funding with other organizations and departments. These are centres which provide urban Aboriginal people essential programming that may have a significant effect on reducing risk factors experienced by Aboriginal people. If properly funded and supported, they may also serve dual roles as both inspiration and a roadmap for other countries (for example, Australia and New Zealand) looking to effect similar changes.

If real reductions want to be made with regard to Aboriginal peoples' victimization, crime and health, and if improvements to overall quality of life are an authentic goal, the government must start recognizing that Aboriginal organizations that are currently in existence may be one way to make a difference. Given that these organizations are well-established and are already delivering many programs, if more funding was given to these Friendship Centres (and other similar centres), they could hire more people, and provide additional programming. Doing this would not only reduce crime and poor health, but also increase program potential and offerings, and the same time increases job opportunities for Aboriginal people working in prevention, counselling and helping professions. Furthermore, if more funds were allocated, Friendship Centres would also be able to start to evaluate many of the programs that they have in operation in order to further determine where successes and improvements need to be made. Ultimately, research shows the potential positives prevention can have, and Aboriginal Centres, such as Friendship Centres already have a head start on such efforts. Therefore expanding and supporting these programs at these centres could prove beneficial on many fronts, most notably in terms of reducing crime and related health costs affecting Aboriginal peoples.

\section{References}

Alfred, T., \& Corntassel, J. (2005). Being Indigenous: Resurgences against contemporary colonialism. Government and Opposition, 40 (4), 597-614.

Astley, S. J. (2004). Fetal alcohol syndrome prevention in Washington State: Evidence of success. Paediatric and Perinatal Epidemiology, 18(5), 344-351.

Bodson, J. Capobianco, L. Leek, J., Lelandais, I., Guillaume, N., Shaw, M., Soria, L., Virgin, M., Ballu, S., Falco, M., \& Guajardo, C. (2008). International Compendium of Crime Prevention Practices. Montreal, QC: International Centre for the Prevention of Crime.

Borowsky, I.W., Resnick, M.D., Ireland, M., \& Blum, R.W. (1999). Suicide attempts among American Indian and Alaska Native youth: Risk and protective factors. Archives of Pediatrics and Adolescent Medicine, 153(6), 573-580.

Brems, C. (1996). Substance use, mental health, and health in Alaska: Emphasis on Alaska Native peoples. Arctic Medical Research, 55(3), 135-147.

Brzozowski, J., Taylor-Butts, A., \& Johnson, S. (2006). Victimization and offending among the Aboriginal population in Canada. Juristat, 26 (3), 1-31. 


\section{First Peoples Child \& Family Review, Volume 7, Number 2, 2013}

Capobianco, L., Shaw, M., \& Dubuc, S. (2003). Crime prevention and Indigenous communities: Current international strategies and programs. Montreal, QC: International Centre for the Prevention of Crime.

Carr, A. (2006). Family therapy: Concepts, process and practice (2nd Ed.). West Sussex, England: John Wiley and Sons Ltd.

Carter, S., Straits, K. J. E., \& Hall, M. (2007). Project Venture: Evaluation of an experiential, culturally-based approach to substance abuse prevention with American Indian youth. Journal of Experiential Education, 29(3), 397-400.

Cerdá M., Diez-Roux, A.V., Tchetgen, E.T., Gordon-Larsen, P., \& Kiefe, C. (2010). The relationship between neighborhood poverty and alcohol use: Estimation by marginal structural models. Epidemiology. 21(4), 482-489.

Chandler, M. J., \& Lalonde, C. (1998). Cultural continuity as a hedge against suicide in Canada's First Nations. Transcultural Psychiatry, 35 (2), 191-219.

Chansonneuve, D. (2007). Addictive behaviours among Aboriginal people in Canada. Ottawa, ON: Aboriginal Healing Foundation.

Chrisjohn, R., Young, S., \& Maraun, M. (2006). The circle game: Shadows and substance in the Indian Residential School experience in Canada. Penticton, BC: Theytus Books Ltd.

Coie, J.D. (1996). Prevention of violence and antisocial Behaviour. In R.D. Peters \& R.J. McMahon (Ed.), Preventing childhood disorders, substance abuse, and delinquency (pp. 1-18). Thousand Oaks, CA: Sage.

Comack, E., Deane, L., Morrissette, L., \& Silver, J. (2009). If you want to change violence in 'hood, you have to change the 'hood: Violence and street gangs in Winnipeg's inner city. Winnipeg, MB: Canadian Centre for Policy Alternatives.

Corrado, R. R., \& Cohen, I. M. (2003). Mental health profiles for a sample of British Columbia's Aboriginal survivors of the Canadian Residential School system. Ottawa, ON: The Aboriginal Healing Foundation.

Cote, H., \& Schissel, W. (2008). Damaged children and Broken spirits: A Residential School survivor story. In Brooks, C. \& Schissel, B. (Eds.) Marginality \& condemnation: An introduction to critical criminology (2nd edition) (pp. 220-237). Black Point, NS: Fernwood Publishing.

Crooks, C. V, Wolfe, D. A., Hughes, R., Jaffe, P. G., \& Chiodo, D. (2008). Development, evaluation and national implementation of a school-based program to reduce violence and related risk behaviour: lessons from the Fourth R. IPC Review, 2, 109-135.

Crossman, A., Sullivan, D.A., \& Benin, M. (2006). The family environment and American adolescents' risk of obesity as young adults. Social Science and Medicine, 63 (9), 2255-2267.

Dilworth-Anderson, P., \& Marshall, S. (1996). Social support in its cultural context. In G.R. Pierce, B.R. Sarason \& I.G. Sarason (Ed.), Handbook of Social Support and the Family (pp.67-79). New York: Plenum Press.

Dishion, T. J., \& Andrews, D.W. (1995). Preventing escalation in problem behaviours with high-risk young adolescents: Immediate and 1-year outcomes. Journal of Consulting and Clinical Psychology, 63, 538-548.

Farrington, D., \& Welsh, B. (2007) Saving children from a life of crime: Early risk factors and effective interventions: New York, NY: Oxford University Press.

Fitzgerald, R. T., \& Carrington, P. J. (2008). The neighbourhood context of urban Aboriginal crime. The Canadian Journal of Criminology and Criminal Justice, 50 (5), 523-557.

Flicker, S. M., Turner, C. W., Waldron, H. B., Brody, J. L., \& Ozechowski, T. J. (2008). Ethnic background, therapeutic alliance and treatment retention in functional family therapy with adolescents who abuse substances. Journal of Family Psychology, 22(1), 167-170.

Fournier, S. \& Crey E. (1997). Stolen from our embrace: The abduction of First Nations children and the restoration of Aboriginal communities. Vancouver, BC: Douglas and McIntyre, Inc. 


\section{Preventing Crime and Poort Health Among Aboriginal People}

Fournier, S., \& Crey E. (2006). Killing the Indian in the child: Four centuries of church-run schools. In R. C.A. Maaka, and C. Anderson (Ed.), The Indigenous experience: Global perspectives (pp. 47-80). Toronto, ON: Canadian Scholars' Press Inc.

Furniss, E. (1995). Victims of benevolence: The dark legacy of the Williams Lake Residential School. Vancouver, BC: Arsenal Pulp Press.

Gagné, M. (1998). The role of dependency and colonialism in generating trauma in First Nations citizens: The James Bay Cree. In Y. Danieli (Eds.), International handbook of multigenerational legacies of trauma (pp. 355-372). New York, NY: Plenum.

Gilchrist, L. D., Schinke, S. P., Trimble, J. E., \& Cvetkovich, G. T. (1987). Skills enhancement to prevent substance abuse among American Indian adolescents. The International Journal of the Addiction, 22 (9), 869-879.

Grant, A. (1996). No end of grief: Indian Residential Schools in Canada. Winnipeg, MB: Pemmican Publications Inc.

Greenwood, P. W., Karoly, L. A., Everingham, S. S., Houbé, J.., Killburn, R. M., Rydell, P. C., Sanders, M., Chiesa, J. (2001). Estimating the costs and benefits of early childhood interventions: nurse home visits and the Perry Preschool. In B. Welsh, D. P. Farrington, \& L. W. Sherman (Eds.), Costs and benefits of preventing crime (pp. 123148). Boulder, CO: Westview Press.

Hahn, A., Leavitt, T., Aaron, P. (1994). Evaluation of the Quantum Opportunities program. Waltham, MA: Brandeis University.

Haig-Brown, C. (1991). Resistance and renewal: Surviving the Indian Residential School. Vancouver, BC: Arsenal Pulp Press Ltd.

Hallett, D., Chandler, M. J., \& Lalonde, C. E. (2007). Aboriginal language knowledge and youth suicide. Cognitive Development, 22 (3), 392-399.

Hastings, R. \& Jamieson, W. (2002). Community mobilization and crime prevention. Report to the National Crime Prevention Centre. Ottawa, ON: Department of Justice Canada.

Heaman, M. I., \& Chalmers, K. (2005). Prevalence and correlates of smoking during pregnancy: A comparison of Aboriginal and non-Aboriginal women in Manitoba. Birth, 32(4), 299-305.

Jaccoud, M., \& Brassard, R. (2003). The marginalization of Aboriginal women in Montréal. In D. Newhouse \& E. Peters (Eds.), Not Strangers in These Parts: Urban Aboriginal People (pp. 131-145). Ottawa, ON: Policy Research Initiative.

Jacobs, B., \& Williams, A. J. (2008). Legacy of Residential Schools: Missing and murdered Aboriginal women. In M. Brant Castellano, L. Archibald \& M. DeGagné, (Eds.), From truth to reconciliation transforming the legacy of Residential Schools (pp. 119-140). Ottawa, ON: The Aboriginal Healing Foundation.

Karoly, L.A., Greenwood, P.W., Everingham, S.S., Hoube, J., Kilburn, M.R., Rydell, C.P.,... Chiesa, J. (1998). Investing in our children: what we know and don't know about the costs and benefits of early childhood interventions. Santa Monica, CA: The RAND Corporation.

Kelly, F. (2008). Confession of a born again Pagan. In M Brant Castellano, L. Archibald \& M. DeGagné, (Eds.), From truth to reconciliation transforming the legacy of Residential Schools (pp. 11-40). Ottawa, ON: The Aboriginal Healing Foundation.

Kendall, G.E., \& Li, J. (2005). Early childhood socialization and social gradients in adult health. Social Science and Medicine, 61, 2272-2276.

Kettl, P., \& Bixler, E.O., (1993). Alcohol and suicide in Alaska Natives. American Indian and Alaska Native Mental Health Research, 5 (2): 34-45

Kirmayer, L. J. (1994). Suicide among Canadian Aboriginal peoples. Transcultural Psychiatric Research Review, 31(1), 3-58. 


\section{First Peoples Child \& Family Review, Volume 7, Number 2, 2013}

Kirmayer, L. J., Simpson, C. \& Cargo, M. (2003). Healing traditions: Culture, community and mental health promotion with Canadian Aboriginal people. Australasian Psychiatry, 11, S15-S23.

Kirmayer, L. J., Brass, G. M., Holton, T., Paul, K., Simpson, C., \& Tait, C. (2007). Suicide among Aboriginal people in Canada. Ottawa, ON: The Aboriginal Healing Foundation.

Kirmayer, L., Fraser, S.-L., Fauras, V., \& Whitely, R. (2009). Current approaches to Aboriginal youth suicide prevention. Montreal: QC: Jewish General Hospital.

Lambertus, S. (2007). Addressing violence perpetrated against Aboriginal women in Alberta. Alberta: Project Lifeline, SLL Research.

Lange, N. E., Bunyavanich, S., Silberg, J. L., Canino, G. , Rosner, B. A., \& Celedón, J. C. (2011).Parental psychosocial stress and asthma morbidity in Puerto Rican twins. The Journal of Allergy and Clinical Immunology, 127(3), 734-740.

La Prairie, C. (1994). Seen but not heard: Native people in the inner City. Ottawa, ON: Department of Justice.

La Prairie, C. (1992). Dimensions of Aboriginal over-representation in correctional institutions and implications for crime prevention. Ottawa, ON: Aboriginal People Collection. Solicitor General Canada.

La Prairie, C. (2002). Aboriginal over-representation in the criminal justice system: A tale of nine cities. Canadian Journal of Criminology, 44 (2), 181-208.

La Prairie, C., \& Stenning, P. (2003). Exile on main street: Some thoughts on Aboriginal over-representation in the criminal justice system. In D. Newhouse \& E. Peters (Eds.), Not Strangers in These Parts: Urban Aboriginal People (pp. 179-193). Ottawa, ON: Policy Research Initiative.

Larson, C. P. (2007). Poverty during pregnancy: Its effects on child health outcomes. Paediatrics \& Child Health, 12(8), 673-677.

Latimer, J., \& Foss, L. C. (2004). A one-day snapshot of Aboriginal youth in custody across Canada: phase II. Ottawa, ON: Research and Statistics Division, Department of Justice Canada.

Linden, R. (2001). Crime prevention in Aboriginal communities. Winnipeg, MB: Consultation Paper, Aboriginal Justice Implementation Commission.

Loppie Reading, C., \& Wein, F. (2009). Health inequalities and social determinants of Aboriginal peoples' health. Prince George, BC: National Collaborating Centre for Aboriginal Health.

Marques, O. (2010). Anxiety in Childhood and Adolescents: Symptomatology, Biopsychosocial Factors and Interventions Used at Family Services à la famille Ottawa. Ottawa: Stuart Peterson Project, Family Services à la famille Ottawa.

Mcleod, J. D., \& Shanahan, M. J. (1996). Trajectories of poverty and children's mental health. Journal of Health and Social Behaviour, 37(3), 207-220.

Mikkonen, J., \& Raphael, D. (2010). Social determinants of health: The Canadian facts. Toronto: York University School of Health Policy and Management.

Milloy, J. (1999). A national crime: The Canadian government and the Residential School system 1879 to 1986. Winnipeg, MB: The University of Manitoba Press.

Mushquash, C. J., Comeau, N. M., \& Stewart, S. H. (2007). An alcohol abuse early intervention approach with Mi'kmaq adolescents. First Nations Child \& Family Review, 3 (1), 17-26.

Monchalin, L. (2010). Canadian Aboriginal peoples victimization, offending, and its prevention: Gathering the evidence. Crime Prevention and Community Safety: An International Journal, 12 (2), 119-132.

Monchalin, L. (2012). Reducing crime affecting urban Aboriginal people: The potential for effective solutions in Winnipeg. Doctoral Dissertation. Ottawa, ON. 


\section{Preventing Crime and Poort Health Among Aboriginal People}

National Association of Friendship Centres. (2009). Business case for the long term sustainability of friendship centres. Ottawa, ON: The National Association of Friendship Centres and The Department of Canadian Heritage.

National Collaborating Centre for Aboriginal Health. (2009). Family violence as a social determinant of First Nations, Inuit and Métis Health. Prince George, BC: National Collaborating Centre for Aboriginal Health.

Olds, D. L., Henderson, C. R., Jr., Kitzman, H. J., Eckenrode, J.J., Cole, R. E., \& Tatelbaum, R.C. (1999). Prenatal and infancy home visitation by nurses: Recent findings. The Future of Children, (9) 1, 44-65.

Perreault, S. (2011). Violent victimization of Aboriginal people in the Canadian provinces, 2009. Juristat, 30 (4), 1-35.

Public Safety Canada. (2011). Corrections and Conditional Release Statistical Overview: Annual Report 2011. Ottawa, ON: Public Safety Canada.

Public Safety Canada. (2007). Healthy Families Project and Kwanlin Dun First Nation's Project: Evaluation summaries. Ottawa, ON: Public Safety Canada.

Rand, J. (2011). Residential Schools: Creating and continuing institutionalization among Aboriginal peoples in Canada. First Peoples Child \& Family Review, 6(1), 56-65.

Reading, J. (2009). The crisis of chronic disease among Aboriginal peoples: A challenge for public health, population health and social policy. Victoria, BC: Centre for Aboriginal Health Research.

Retnakaran, R., Hanley, A. J. G., Connelly, P. W., Harris, S. B., \& Zinman, B. (2005). Cigarette smoking and cardiovascular risk factors among Aboriginal Canadian youths. Canadian Medical Association Journal, 173(8), 885-889.

Rice, B., \& Snyder, A. (2008). Reconciliation in the context of a settler society: Healing the legacy of colonialism in Canada. In M. Brant Castellano, L. Archibald, \& M. DeGagné (Eds.), From truth to reconciliation transforming the legacy of Residential Schools (pp. 43-61). Ottawa: ON: The Aboriginal Healing Foundation.

Sampson, R. J., \& Laub, J. H. (1993). Crime in the making: Pathways and turning points through life. Cambridge, MA: Harvard University Press.

Sanders M., Markie-Dadds, C. \& Turner, K.M. T. (2003). Theoretical, scientific and clinical foundations of the Triple P-Positive Parenting Program: A population approach to the promotion of parenting competence. Queensland, Australia: The University of Queensland: The Parenting and Family Support Centre.

Sandler, I. N., Schoenfelder, E. N., Wolchik, S. A., \& MacKinnon, D. P. (2011). Long-term impact of prevention programs to promote effective parenting: Lasting effects but uncertain processes. Annual Review of Psychology, 62 (1): 299-329

Seale, J.P., Shellenberger, S., \& Spense J. (2006). Alcohol problems in Alaska natives: Lessons from the Inuit. American Indian \& Alaskan Native Mental Health Research: The Journal of the National Center, 13(1): 1-31

Schweinhart, L. (2005). The High/Scope Perry Preschool study through age 40: Summary conclusions and frequently asked questions. Ypsilanti, MI: High/Scope Press.

Segal, B. (1999). Alaska Natives combating substance abuse and related violence through self-healing. Anchorage, AK: Center for Alcohol and Addictions Studies, University of Alaska.

Sexton, T., \& Turner, C. W. (2010). The effectiveness of functional family therapy for youth with behavioural problems in a community practice setting. Journal of Family Psychology, 24(3), 339-348.

Shawanda, G. (2010). Voice of an Elder: Zhaawonde - dawn of a new day. First Peoples Child \& Family Review. 5 (1), 22-39.

Sherman L. W., Farrington D. P., Welsh, B. C., Mackenzie, D. L. (2002) Evidence-based crime prevention. Routledge. London.

Sherman, L. W., Gottfredson, D.C., Mackenzie, D., Eck, J., Reuter, P., \& Bushway, S. (1997). Preventing crime: What works, what doesn't, what's promising. Washington. US Department of Justice. 


\section{First Peoples Child \& Family Review, Volume 7, Number 2, 2013}

Smith, T. E., Sells, S. P., Rodman, J., \& Reynolds, L. R. (2006). Reducing adolescent substance abuse and delinquency: Pilot research of a family-oriented psychoeducation curriculum. Journal of Child \& Adolescent Substance Abuse, 15(4), 105-115.

Statistics Canada. (2006). Aboriginal people in Canada in 2006: Inuit, Métis, and First Nations, 2006 Census. Ottawa, ON: Canadian Centre for Justice Statistics.

Statistics Canada. (2005). Family violence: A statistical profile 2005. Statistics Canada, Ottawa: ON.

Streissguth, A. P., Bookstein, F. L., Barr, H. M., Sampson, P. D., O’Malley, K., \& Kogan Young, J. (2004). Risk factors for adverse life outcomes in Fetal Alcohol Syndrome and Fetal Alcohol effects. Development and Behavioral Pediatrics, 25(4), 228-238.

Tjepkema, M. (2002). The health of the off-reserve Aboriginal population: Supplement to health reports. 13, Ottawa, ON: Statistics Canada

Totten, M. (2009). Aboriginal youth and gang involvement in Canada: Quality prevention strategies. IPC Review, (3),135-156.

Turner K. M., Richards, M. \& Sanders, M.R. (2007). Randomised clinical trial of a group parent education programme for Australian Indigenous families. Journal of Paediatrics and Child Health, 43, 429-437.

Utting, D. (2003). Prevention through family and parenting program. In D. P. Farrington \& J.W. Coid, (Eds.) Early prevention of adult antisocial behaviour (pp. 243-264). Cambridge: Cambridge University Press.

Waller, I. (2006). Less law, more order: The truth about reducing crime. Westport, CT: Praeger Publishers.

Waller, I., Sansfaçon, D., \& Welsh, B. (1999). Crime prevention digest II: comparative analysis of successful community safety. Montreal, QC: International Centre for the Prevention of Crime.

Waller, I. \& Weiler, D. (1984). Crime prevention through social development: an overview with sources. Ottawa, ON: Canadian Council on Social Development.

Welsh, B. C., \& Farrington, D. P. (2002). What works, what doesn't, what's promising, and future directions. In L. W. Sherman, D. P. Farrington, B. C. Welsh, D. Layton Mackenzie (Eds.), Evidence-based crime prevention (pp. 405420), London: Routledge.

World Health Organization. (2004). Preventing violence: A guide to implementing the recommendations for the World Report on Violence and Health. Geneva: Violence and Injuries Prevention.

World Health Organization. (2002). World report on violence and health. Geneva: Violence and Injuries Prevention.

Yuan, N. P., Koss, M. P., Polacca, M., \& Goldman, D. (2006). Risk factors for physical assault and rape among six Native American tribes. Journal of Interpersonal Violence, 21(12), 1566-1590.

Zahradnik, M., Stewart, S. H., O’Connor, R. M., Stevens, D., Ungar, M., \& Wekerle, C. (2010). Resilience moderates the relationship between exposure to violence and posttraumatic reexperiencing in Mi'kmaq youth. International Journal of Mental Health and Addiction, 8: 408-420. 